movement. Improvements in rotational movement were seen only with the intra-articular injection.

These results might be improved if patients with pain confined to the posterosuperior region of the shoulder, which is said to respond selectively to a nerve block, ${ }^{5}$ were treated.

1 Harris ED. Rheumatoid arthritis: the clinical spectrum. In: Kelly WN, Harri ED, Ruddy S, Sledge CB. Textbook of rheumatology. 3rd ed. Philadelphia: W B Saunders, 1989:930-1.
2 Eriksson E. Illustrated handbook of local anaesthesia. London: Lloyd Luke, 1979:85

3 Arnett FC, Edworthy SM, Bloch DA. The American Rheumatism Association, 1987. Revised criteria for the classification of rheumatoid arthritis. Arthritis Rheum 1988;31:315-23.

4 Ritchie DM, Boyle JA, McInnes JM, et al. Clinical studies with an articular index for the assessment of joint tenderness in patients with rheumatoid arthritis. Of Med 1968;147:393-406.

5 Brown DE, James DC, Roy S. Pain relief by suprascapular nerve block in glenohumeral arthritis. Scand f Rheumatol 1988;17:411-5.

(Accepted 24 fuly 1989)

\section{Cholestasis induced by oestrogen after liver transplantation}

\author{
Donna M Fedorkow, Bernard Corenblum, \\ Eldon A Shaffer
}

\section{Divisions of}

Gastroenterology and

Endocrinology,

Department of Medicine,

University of Calgary,

Calgary, Alberta, Canada

Donna M Fedorkow, FRCSC, resident

Bernard Corenblum, FRCPC, professor

Eldon A Shaffer, FRCPC professor

Correspondence to: $\operatorname{Dr} \mathrm{E} A$

Shaffer, Division of

Gastroenterology,

University of Calgary,

Calgary, Alberta T2N 4N1,

Canada.

BrMed f 1989;299:1080-1
Successful liver transplantation is not usually associated with hepatic dysfunction, though both low grade rejection and cyclosporin can induce cholestasis. ${ }^{.}$Natural and synthetic oestrogens also alter hepatic excretory function, occasionally inducing overt cholestasis in susceptible women. ${ }^{2}$ We report on a woman who developed cholestasis associated with oral oestrogen treatment after receiving an orthotopic liver transplant.

\section{Case report}

A 20 year old nulligravid woman had had well documented chronic active hepatitis since the age of 5 , which had been confirmed by liver biopsy. Other causes of chronic hepatitis had been excluded. Despite corticosteroid treatment for 12 years cirrhosis and oesophageal varices had developed, causing recurrent severe upper gastrointestinal bleeding. Sclerotherapy had proved unsuccessful. She underwent successful liver transplantation. Postoperatively immunosuppression was maintained with cyclosporin $200 \mathrm{mg}$ twice daily and prednisone $10 \mathrm{mg}$ daily. Trough serum cyclosporin concentrations determined by radioimmunoassay remained in the therapeutic range (figure). Within four weeks of the operation results of liver function tests were normal.

Menarche at age 12 had been followed by normal menses, but she had become amenorrhoeic when ill with the repeated gastrointestinal haemorrhages. After transplantation her menstrual periods resumed and were normal for four months. Severe menorrhagia then developed, resulting in anaemia. This heavy menstrua bleeding was not relieved by treatment with a low dose oral contraceptive (ethinyloestradiol $35 \mu \mathrm{g}$ ) but responded to a higher dose $(50 \mu \mathrm{g})$. While receiving this higher dose she developed pruritus and biochemical evidence of intrahepatic cholestasis (figure). Withdrawing the oestrogen promptly relieved her pruritus and normalised the liver enzyme activities, but the menorrhagia returned. A final vaginal haemorrhage was managed with ethinyloestradiol $50 \mu \mathrm{g}$ daily for one week. This second challenge again precipitated pruritus and hepatic dysfunction (figure).

The menorrhagia was controlled by an analogue of gonadorelin, leuprorelin acetate, $1 \mathrm{mg}$ daily, and she was also given transdermal oestrogen (a $50 \mu \mathrm{g}$ patch twice weekly). A normal menstrual cycle was mimicked by giving medroxyprogesterone acetate $10 \mathrm{mg}$ on days $20-27$ of each cycle. This regimen produced regular withdrawal bleeding and stable haemoglobin concentrations and results of liver function tests, and she did not have pruritus.

The patient's family history was non-contributory. The donor of the liver had died from a subarachnoid haemorrhage; she had not had a history of liver disease during any of her pregnancies or when taking oral contraceptives.

\section{Comment}

The resolution of this patient's pruritus and normalisation of biochemical abnormalities after withdrawal of the high doses of oestrogen on two occasions support an aetiological association between the ethinyloestradiol and cholestasis. Further oestrogen treatment was given transdermally to avoid the first pass effect on the liver. She had not received oestrogen before liver transplantation because of the chronic hepatitis. Her age and response to the operation made fertility seem
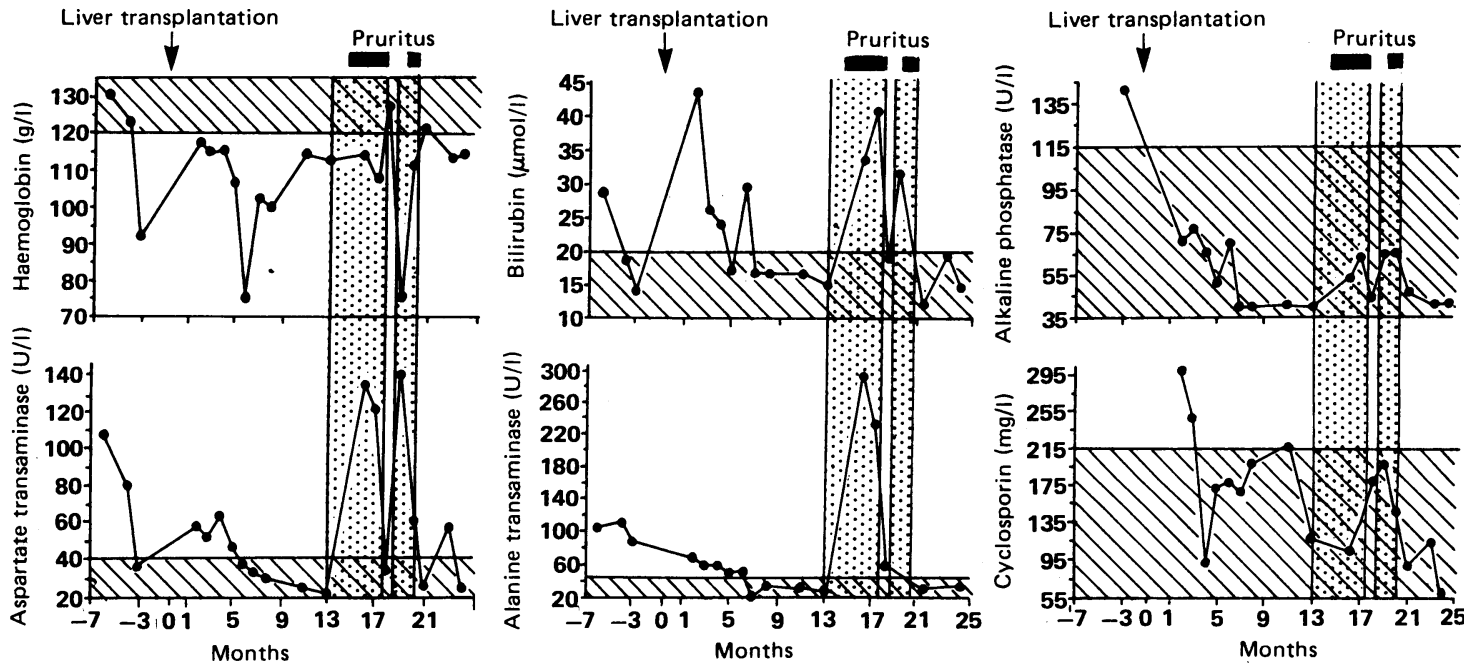

Biochemical concentrations before and after liver transplantation and during administration of ethinyloestradiol (shown by vertical stippled columns). Hatched horizontal areas indicate normal ranges 
likely as pregnancy can occur after liver transplantation. ${ }^{3}$ We therefore did not perform a hysterectomy for the menorrhagia.

The patient's negative family history and the donor's negative history negate a genetic basis for cholestasis associated with pregnancy or sex hormones. Rejection of a transplant and cyclosporin, however, can induce low grade cholestasis. Oestrogen may have elicited such an underlying defect much as it can unmask primary biliary cirrhosis that first presents as cholestasis (pruritus) during pregnancy. ${ }^{+}$Thus after liver trans- plantation perhaps primed by treatment with cyclosporin oestrogen may elicit cholestasis.

1 Stone BG, Udani AS, Warty V, Plocki K, Bedetti CD, Van Thiel DH. Cyclosporin A-induced cholestasis: the mechanism in a rat model. Gastroem terologv 1987:93:344-51.

2 Shaffe EA. The liver and pregnancy: update. Current Problems in Obstetrics, Gynecology and Fertility 1987;10:439-501.

3 Walcott WO, Derick DE, Jolley JJ, Snyder DL, Schmid R. Successful pregnancy in a liver transplant patient. Am f Obstel Gynecol 1978;132:340-1. 4 Sherlock S. Primary biliary cirrhosis. In: Schiff L, Schiff ER, eds. Diseases of the liver. Philadelphia: Lippincott, 1987:979-99.

(Accepted 2 August 1989)

\section{Bronchodilator effect of atrial natriuretic peptide in asthma}

\author{
G Hulks, A Jardine, J M C Connell, \\ N C Thomson
}

Department of Respiratory Medicine, Western Infirmary, Glasgow G11 6NT

G Hulks, MRCP, research registrar

N C Thomson, $M D$, consultant physician

Medical Research Council Blood Pressure Unit,

Western Infirmary,

Glasgow

A Jardine, MRCP, research

registrar

J M C Connell, MD,

consultant physician

Correspondence to: $\mathrm{Dr}$ Hulks.

Br Med $\mathcal{F}$ 1989;299:1081-2 bronchomotor tone in asthmatic subjects.

\section{Subjects, methods, and results}

Atrial natriuretic peptide relaxes vascular smooth muscle directly, but little interest has been expressed in its effect on airway smooth muscle despite an in vitro study showing a dose dependent relaxant effect on guinea pig trachea.' This effect has since been observed on tone induced by agonists in vitro, ${ }^{2}$ and a recent in vivo study showed that infusions of atrial natriuretic peptide increased basal airway conductance and reversed bronchoconstriction induced by leukotriene $\mathrm{D}_{4}$ in the same animal model. ${ }^{3}$ We examined the effect of infused atrial natriuretic peptide on

We studied eight subjects (two women; mean (SD) age $39.7(8 \cdot 8)$ years). Each had moderately severe asthma: mean forced expiratory volume in one second was $47 \cdot 2(9 \cdot 8) \%$ of the predicted value and was improved in each subject by $>25 \%$ by inhaled salbutamol. Inhaled bronchodilator agents were withheld for 10 hours, but other inhaled treatment was continued as usual. Written informed consent was obtained and the study approved by Glasgow West ethical committee.

On each of two study days an indwelling venous cannula was inserted into each forearm and the subject relaxed for 20 minutes. We then measured forced expiratory volume in one second (taken as the best of three attempts) with a dry wedge spirometer (Vitalograph) and blood pressure and pulse rate with a semiautomatic sphygmomanometer; we withdrew $20 \mathrm{ml}$ blood to estimate plasma atrial natriuretic peptide concentration by radioimmunoassay ${ }^{4}$ and catecholamine concentrations. After these baseline measurements an intravenous infusion of either atrial natriuretic peptide or placebo was administered in a double blind, randomised manner. Doses of peptide corresponded to $0.5,2 \cdot 0$, and $10.0 \mathrm{pmol} / \mathrm{kg} / \mathrm{min}$ and were given for 20 minutes each in incremental fashion. At the end of each infusion period forced expiratory volume in one second, pulse, blood pressure, and atrial natriuretic peptide and catecholamine concentrations were measured. After the last dose had been completed the infusion was stopped and each subject received $5 \mathrm{mg}$ nebulised salbutamol; final measurements were taken 20 minutes thereafter. The significance of the data was assessed by two way analysis of variance.

The forced expiratory volume in one second rose significantly at the highest rate of infusion with a mean increase of 0.50 ( $95 \%$ confidence interval 0.23 to $0 \cdot 78)$ litre (equivalent to $31.5(14.9$ to $48 \cdot 1) \%$ ) from the baseline value $(p<0.01$; figure). It tended to rise at an

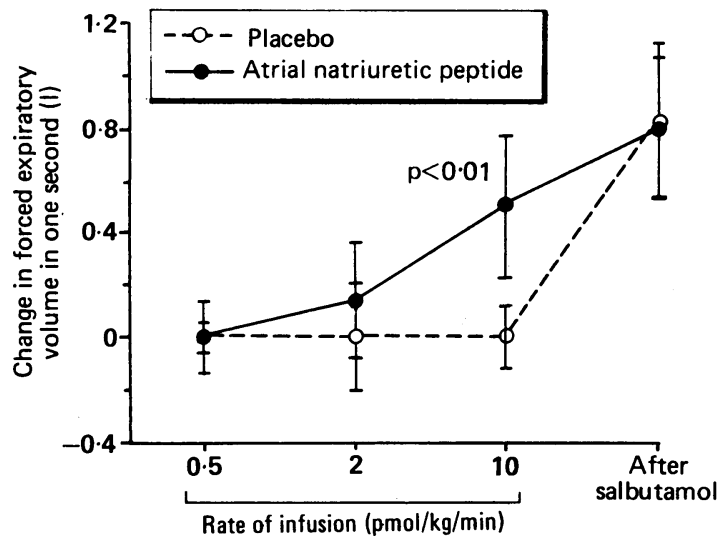

Mean change in forced expiratory volume in one second with varying rates of intravenous infusion of atrial natriuretic peptide compared with placebo $(n=8)$. Nebulised salbutamol $(5 \mathrm{mg})$ was given after final infusion. Vertical bars represent $95 \%$ confidence intervals

infusion rate of $2 \mathrm{pmol} / \mathrm{kg} / \mathrm{min}$, but this was not significant. Overall, the response varied considerably: some subjects responded appreciably to the middle infusion dose while one subject did not respond at all even to the highest dose. No side effects were reported during the active and placebo studies. The mean plasma atrial natriuretic peptide concentration was 10 (95\% confidence interval 6 to 15 ) $\mathrm{nmol} / \mathrm{l}$ basally (normal $2-17 \mathrm{nmol} / \mathrm{l}$ ); this rose to 12 (8 to 16$) \mathrm{nmol} / 1,43$ (33 to 53 ) nmol/l, and 252 (220 to 285 ) nmol// with increasing rates of infusion and had fallen to 12 (11 to 18) $\mathrm{nmol} / \mathrm{l} 20$ minutes after salbutamol.

Baseline pulse, blood pressure, and catecholamine concentrations were comparable, and variation in these measurements between the two study days was not significant.

\section{Comment}

We believe this to be the first report of the effects of atrial natriuretic peptide in asthmatic subjects; we found that it had considerable bronchodilator properties. In many tissues atrial natriuretic peptide alters intracellular events through generating cyclic guanosine monophosphate, and preliminary evidence suggests that a similar action occurs in tracheal smooth muscle. ${ }^{5}$ Although specific receptors have been identified in pulmonary tissue, they have not so far been found in airway smooth muscle. In lung disease atrial natriuretic peptide has been assumed to act as a pulmonary vasodilator in addition to having peripheral renal and vascular action. Our findings suggest that important effects on airway tone may also occur; further studies to explore the peptide's role in pulmonary physiology and disorders of airway tone are indicated.

1 O'Donnell M, Garippa R, Welton AF. Relaxant effect of atriopeptins in isolated guinea-pig airway and vascular smooth muscle. Peptides 1985;6:597-601. 2 Hamel R, Ford-Hutchinson AW. Relaxant profile of synthetic atrial natriuretic factor on guinea-pig pulmonary tissues. Eur $\mathcal{F}$ Pharmacol 1986;121:151-5. 3 Englebach IM, Lappe RW, Hand JM. Bronchoprotective and bronchodilator 